\title{
EXPLORING GIFTED AND TALENTED MUSLIMS STUDENT'S PERFORMANCE USING GEOGEBRA IN TEACHING AND LEARNING MATHEMATICS
}

\author{
NORAZLINA SUBANI*, MUHAMMAD ZAIM MOHAMAD SHUKRI \& MUHAMAD \\ ARIF SHAFIE MOHD NASRUL
}

\begin{abstract}
GeoGebra is a teaching tool that educators use in their lesson plans to improve the quality of teaching and learning. Instead of drawing on a sheet of paper, students can design a graph, adjust the actual graph shape, and examine the impact of changing graph pattern using GeoGebra in mathematics teaching and learning. Furthermore, students can keep all of their work materials in a structured manner for future reference. GeoGebra will make a school lecture more interesting, exciting, creative, and innovative. The goal of this study was to analyse the effects of GeoGebra software in Mathematics achievement in respect to quadratic functions among gifted and talented Muslims student's at Kolej GENIUS Insan, Universiti Sains Islam Malaysia. The maximum or minimum point of quadratic function was determined by using GeoGebra software, and the characteristics of quadratic expressions in one variables was also identified. The results illustrate that the graph quadratic expression has the highest point or the lowest point based the values of coefficient a on the quadratic function. For the graph function with negative values of coefficient a on a quadratic function, there are highest values of coordinates $x$ and $y$, which also known as maximum point, while the graph function with positive values of a on a quadratic function, there are lowest values of coordinates $x$ and $y$, which also known as minimum point. When students utilize GeoGebra software, their performance in calculating the minimum and maximum points on quadratic functions improves.
\end{abstract}

Keywords: Geogebra; Integrated naqli 'aqli gifted education; Gifted muslims student; Mathematics achievement; Quadratic functions

\section{INTRODUCTION}

Nowadays, technology is becoming an important powerful component. Many educational academics have conducted their classroom on incorporating technology into education in attempt to improve teaching and learning quality (Preiner 2008). Teaching and learning are the two fundamental components of mathematics education that are acknowledged by the use of digital technology in the classroom (Laborde 2014). Several research has been conducted into how students use digital technology and how educators implement GeoGebra into their lesson plans.

According to Pannen (2014), digital technology, such as GeoGebra as an integrated component of teaching and learning, especially in learning experiences to become more innovative, accelerated, and improved, and also increasing academic skills performance and students learning. Furthermore, GeoGebra use in mathematics education not only helps students construct their visual representation of mathematical ideas and concepts, summarize 
and analyse data, and interpret data, but also enables them to investigate every area of mathematics, such as geometry, algebra and statistics (Hohenwarter et al. 2009).

Markus Hohenwarter was developed GeoGebra in year 2001, and it is a free program that could be downloaded from www.geogebra.org. (Hohenwarter et al. 2008). This software has been translated into 36 languages so that it can be used by people from all around the world. As a result, it looks to be a user-friendly software that can be used intuitively and does not required advanced knowledge to use (Domènech 2009; Dogan \& İçel 2011; Saha et al. 2010).

According to Furner and Marinas (2012), GeoGebra may be used to teach and study mathematics in a variety of ways such as for demonstration and visualization, GeoGebra may provide diverse representations, provides basic characteristics of Computer Algebra System (CAS) to bridge gaps between geometry, algebra, and calculus, and it may be used as a building tool because it can create shapes.

In basic and secondary education, however, mathematics is concerned with abstract concepts (Okafor \& Anaduaka 2013). At these levels of education, mathematics syllabus such as geometry, algebra, and calculus are deemed overly abstract and hence difficult to understand by a huge portion of the students. As a result, both skill and interest in mathematics have decreased (Fahlberg-Stojanovska \& Stojanovski 2009).

According to previous research, many educators implement GeoGebra in their lesson plans, particularly when teaching geometry concepts (Battista 1999; Dogan \& İçel 2011; Dolbilin 2004; Domènech 2009; Furner \& Marinas 2012; Idris 2006; Kaushal \& Chun-Yen 2015; Laborde 2014; Mammana \& Villani 1998; Saha et al. 2010). The teaching of Euclidean geometry should begin in the primary school years. Students should be able to recognize and investigate various geometrical shapes and their attributes (Mammana \& Villani 1998).

According to Dolbilin (2004), many studies have proven that teaching and understanding mathematics, particularly geometry, is challenging. The visualization and exploration skills required for geometrical concepts, problem-solving skills, and geometry reasoning are frequently neglected by students (Battista 1999; Idris 2006). According to Idris (2006), students are discouraged by their lack of comprehension of geometry, which leads to reduced performance in the subject.

In this research, the effects of GeoGebra software in Mathematics achievement in respect to quadratic functions among gifted and talented Muslims student's at Kolej GENIUS Insan, Universiti Sains Islam Malaysia were determined. The maximum or minimum point of quadratic function was determined by using GeoGebra software, and the characteristics of quadratic expressions in one variables was also identified.

\section{METHODOLOGY}

\section{Mathematical Equation}

A quadratic function in one variable is a function whereby the highest power for the variables is two. The general form of quadratic function is written in the form of:

$$
f(x)=a x^{2}+b x+c
$$

where $a, b$ and $c$ are constants and $a \neq 0$, and $x$ is a variable.

There are only two shapes of the graph of $f(x)=a x^{2}+b x+c, a \neq 0$. The value of coefficient $a$ determines the shape of the graph, where the curved of the graph of a quadratic is called as a 
parabola. For a positive values of $a, a>0$ the shape of the is likes $\cup$ shape, while the shape is likes $\cap$ for negative values of $a, a<0$ (Choo et al. 2019; Kiong et al. 2019). The maximum or minimum point of quadratic function and the characteristics of quadratic expressions in one variables were determined by using GeoGebra software.

\section{Data Collection}

A total of 100 students from 4 classes were surveyed as respondents consisting of $51 \%$ male and $49 \%$ female Form 1 and Form 5 students. This survey was made specifically for analyse the effects of GeoGebra software in Mathematics achievement in respect to quadratic functions among gifted and talented Muslims student's at Kolej GENIUS Insan, Universiti Sains Islam Malaysia.

\section{RESULTS AND DISCUSSION}

\section{Effects of Maximum and Minimum Point}

Figure 1 shows the graph of a maximum and minimum point of quadratic functions plotting by using GeoGebra software. Figure 1(a) illustrated the minimum point at $(-2.5,-12.25)$ for a quadratic function $f(x)=x^{2}+5 x-6$, where $a>0$. Figure 1(b) illustrated the minimum point at $(2.5,0.25)$ for a quadratic function $f(x)=-x^{2}+5 x-6$, where $a<0$. Changing in value of $a$ affects the shape of the graph, where $a>0$, the shape of the graph is $\cup$ which passes through the minimum point and when $a<0$, the shape of the graph is $\cap$ which passes through the maximum point. By using the GeoGebra software, the maximum and minimum point of the graph can be determined through the plotting process, without calculation.

Figure 2 shows the minimum point of quadratic function plotting by using GeoGebra software, where the value of coefficient $b$ in quadratic functions changed. Changing in value of $b$ only affects the position of vertex with respect to the $y$-axis, however the shape of the graph and the $y$-intercept are unchanged. The results show that the graph $a>0$, when $b>0$, the vertex is on the left side of the $y$-axis and when $b<0$, the vertex is on the right side of the $y$-axis. Based on the characteristics of changing the coefficients of quadratic functions, when the graph $a<0$, and $b>0$, the vertex is on the right side of the $y$-axis and when $b<0$, the vertex is on the left of the $y$-axis, while the vertex is on the $y$-axis when $b=0$. 


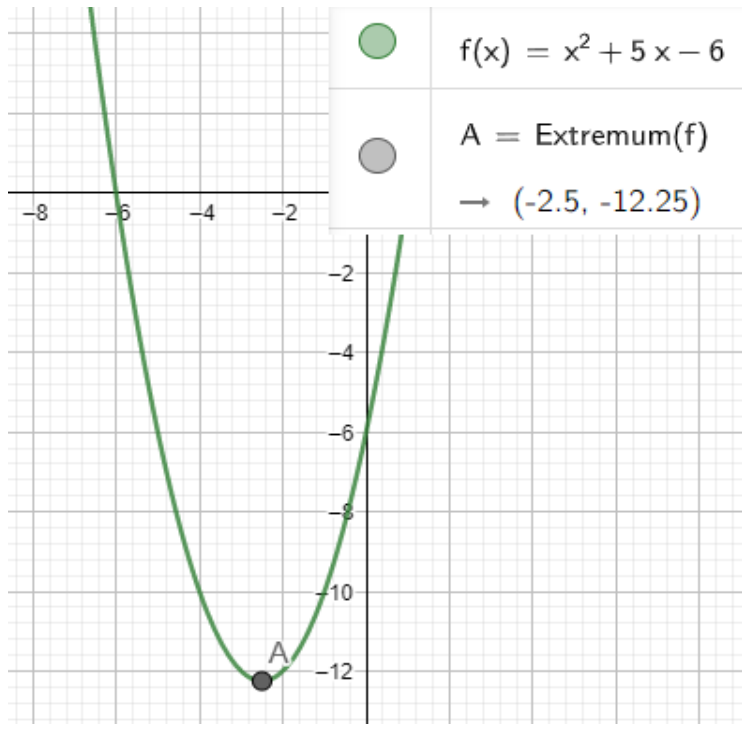

(a) Minimum point at $(-2.5,-12.25)$

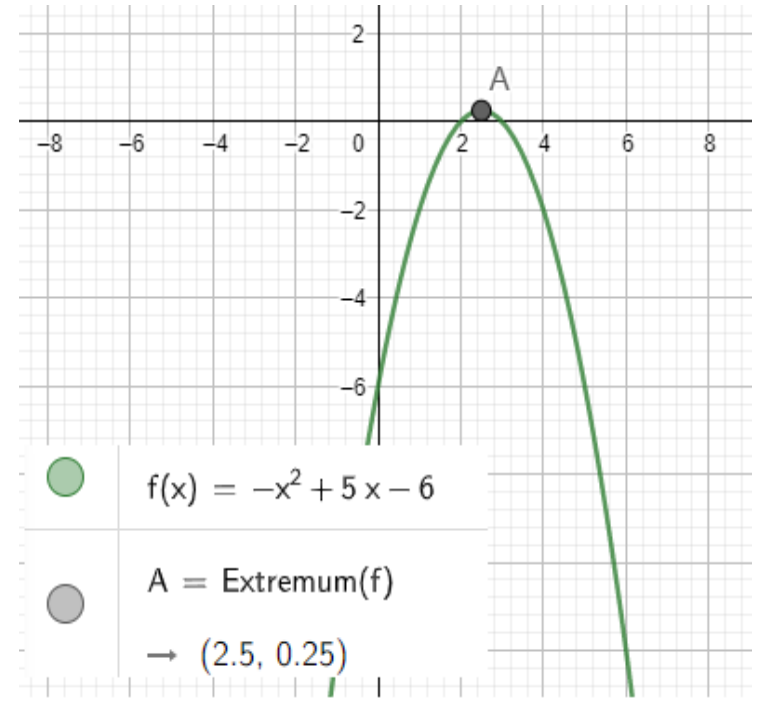

(b) Maximum point at $(2.5,0.25)$

Figure 1. Graph of a maximum or minimum point plotting by using GeoGebra software.

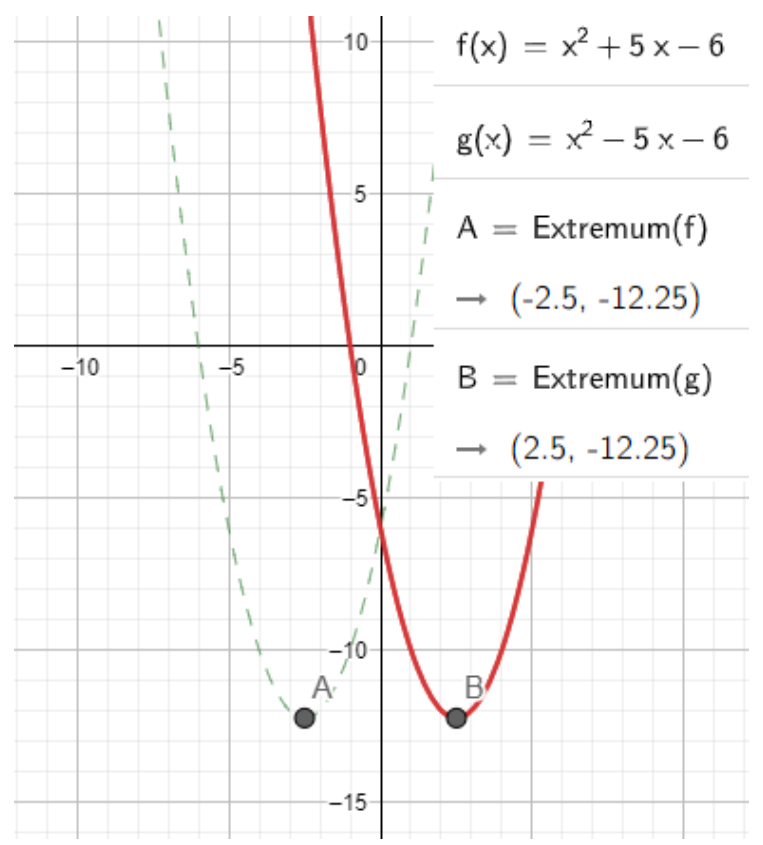

Figure 2. Minimum point plotting by using GeoGebra software.

Gifted and Talented Muslim Student's Performance Analysis

Figure 3 shows $61 \%$ of gifted and talented muslim students at Kolej GENIUS Insan have been using GeoGebra software during Mathematics class, while 39\% students did not used the GeoGebra software during Mathematics class. This software was implemented for Form 1 and Form 5 students in Mathematics subject. Based on Figure 4, 67.8\% of students acknowledged 
that they knew about this GeoGebra from their school, while the remaining students claimed to know about this software from their family (home), tuition classes or other sources.

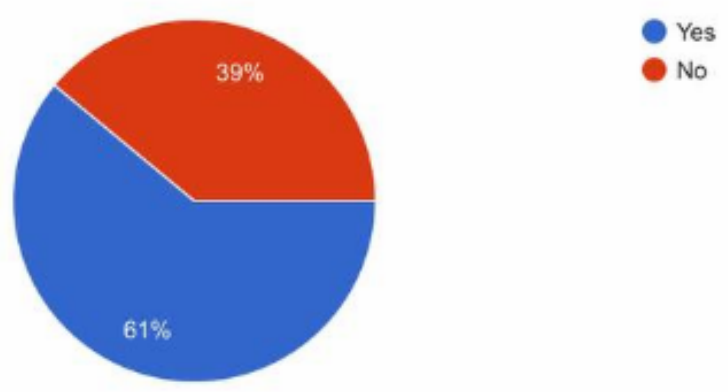

Figure 3: Percentage of KGI's student use GeoGebra software

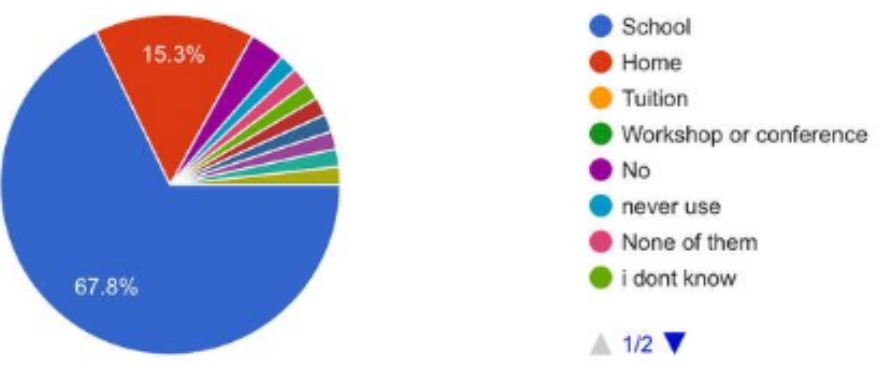

Figure 4: Percentage of KGI's student use GeoGebra software

Based on the survey, 53\% students agreed that the GeoGebra software was fun, enjoyable and also increased their academic skills learning, while $44 \%$ were neutral and only $3 \%$ students did not agree with this statement. Majority of the students agreed that this software was useful for learning mathematics, interpreting mathematical concepts, increasing confidence, creative thinking, making learning more interesting, and visualizing mathematical content. These results are shown in Figure 5. Most students who have implemented this software recommended that this software be implemented during learning process to enhance students' achievement and conceptual understanding. From the results of this study, it is recommended that lecturers utilize this technology while teaching students on constructing a graph of quadratic functions in their classes.

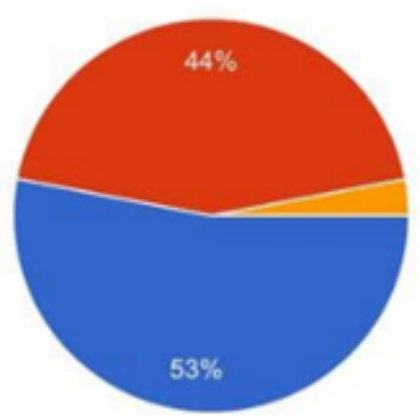

Figure 5: Percentage of KGI's student agree that GeoGebra software is fun and enjoyable tools. 


\section{CONCLUSION}

GeoGebra is an effective tool/software for teaching quadratic functions and has a significant effect on students' achievement in quadratic functions. Students agreed that this software was useful for learning mathematics, interpreting mathematical concepts, increasing confidence, creative thinking, making learning more interesting, and visualizing mathematical content. Students can construct a graph, modify and observe the effects of changing graph shape. The main objectives of this research was to analyse the effects of GeoGebra software in Mathematics achievement in respect to quadratic functions among gifted and talented Muslims student's at Kolej GENIUS Insan, Universiti Sains Islam Malaysia. The maximum or minimum point of quadratic function was determined by using GeoGebra software, and the characteristics of quadratic expressions in one variables was also identified. The results illustrated that the graph quadratic expression has the highest point or the lowest point based the values of coefficient $a$ on the quadratic function. For the graph function with negative values of coefficient $a$ on a quadratic function, there were highest values of coordinates $x$ and $y$, which also known as maximum point, while the graph function with positive values of $a$ on a quadratic function, there are lowest values of coordinates $x$ and $y$, which were also known as the minimum point. The results of the research showed that this software is extremely valuable and useful to improve students' achievement and conceptual understanding. As a result, lecturers should utilize this technology while teaching students on constructing a graph of quadratic functions in their classes. Furthermore, it is suggested that curriculum developers and textbook writers include such kind of activities which are based on mathematics software in the curriculum.

\section{CONFLICT OF INTERESTS}

The authors declare that there is no conflict of interests regarding the publication of this paper.

\section{ACKNOWLEDGEMENTS}

Kolej GENIUS Insan and Universiti Sains Islam Malaysia, are gratefully acknowledged.

\section{REFERENCES}

Battista, M. T. 1999. Geometry results from the third international mathematics and science study. Teaching Children Mathematics 5(6): 367-373.

Choo, Y. P., Renu, T., Raman, K., Wen, W. J. and Santhanasamy, V. D. S. 2019. Kurikulum Standard Sekolah Menengah Dual Language Programme Mathematics Form 4. Sasbadi Sdn. Bhd. Malaysia: Selangor Darul Ehsan.

Dogan, M., and İçel, R. 2011. The role of dynamic geometry software in the process of learning: GeoGebra example about triangles. Journal of Human Sciences 8(1): 14411458.

Dolbilin, N. 2004. Geometry in Russian Schools: Traditions of Past and State in Present. Proceedings of the $9^{\text {th }}$ International Congress on Mathematical Education, pp. 118-120

Domènech, N. I. 2009. Influence of Dynamic Geometry Software on Plane Geometry Problem Solving Strategies. Doctoral Dissertation of University of Autònoma de Barcelona. 
Fahlberg-Stojanovska, L., and Stojanovski, V. 2009. GeoGebra - Freedom to explore and learn. Teaching Mathematics and its Applications 28(2): 69-76.

Furner, J. M., and Marinas, C. A. 2012. Connecting Geometry, Measurement, And Algebra Using Geogebra for The Elementary Grades. In Twenty-fourth Annual International Conference on Technology in Collegiate Mathematics, pp. 63-72.

Hohenwarter, J., Hohenwarter, M., and Lavicza, Z. 2009. Introducing dynamic mathematics software to secondary school teachers: The case of GeoGebra. Journal of Computers in Mathematics and Science Teaching 28(2): 135-146.

Hohenwarter, M., Hohenwarter, J., Kreis, Y., and Lavicza, Z. 2008. Teaching and Calculus with Free Dynamic Mathematics Software GeoGebra. In $11^{\text {th }}$ International Congress on Mathematical Education.

Idris, N. 2006. Teaching and Learning of Mathematics: Making Sense and Developing Cognitives Ability. Kuala Lumpur: Utusan Publications \& Distributors Sdn. Bhd.

Kaushal, K. B., and Chun-Yen, C. 2015. Incorporating GeoGebra into geometry learning-a lesson from India. Eurasia Journal of Mathematics, Science \& Technology Education 11(1): 77-86

Kiong, W. M, Musa, Z., Kamar, A., Ahmad, S., Zaki, N., and Borhan, Z. H. 2019. Kurikulum Standard Sekolah Menengah Dual Language Programme Additional Mathematics Form 4. Pelangi Sdn. Bhd. Malaysia: Selangor Darul Ehsan.

Laborde, C. 2014. Interactivity and Flexibility Exemplified with Cabri. In Plenary lecture given at the Asian Technology Conference in Mathematics.

Mammana, C. and Villani, V. (eds.) 1998. Perspectives on the Teaching of Geometry for the $21^{\text {st }}$ Century, An ICMI Study. The Netherlands: Kluwer Academic Publishers.

Okafor, C. F., and Anaduaka, U. S. 2013. Nigerian school children and mathematics phobia: how the mathematics teacher can help. American Journal of Educational Research 1(7): 247-251.

Pannen, P. 2014. Integrating Technology in Teaching and Learning Mathematics. In Electronic Proceedings of the $19^{\text {th }}$ Asian Technology Conference in Mathematics. Yogyakarta: Indonesia.

Preiner, J. 2008. Introducing Dynamic Mathematics Software to Mathematics Teachers: The Case of GeoGebra.

Saha, R. A., Ayub, A. F. M., and Tarmizi, R. A. 2010. The effects of GeoGebra on mathematics achievement: Enlightening coordinate geometry learning. Procedia-Social and Behavioral Sciences 8: 686-693.

NORAZLINA SUBANI

Kolej GENIUS Insan,

Universiti Sains Islam Malaysia,

Bandar Baru Nilai, 71800, Nilai, Negeri Sembilan, Malaysia

MUHAMMAD ZAIM MOHAMAD SHUKRI

Kolej GENIUS Insan,

Universiti Sains Islam Malaysia,

Bandar Baru Nilai, 71800, Nilai, Negeri Sembilan, Malaysia

MUHAMAD ARIF SHAFIE MOHD NASRUL

Kolej GENIUS Insan,

Universiti Sains Islam Malaysia,

Bandar Baru Nilai, 71800, Nilai, Negeri Sembilan, Malaysia 
Corresponding author: norazlina.subani@usim.edu.my

Received: 11 August 2021 / Accepted: 26 October 2021 / Published: 20 November 2021 